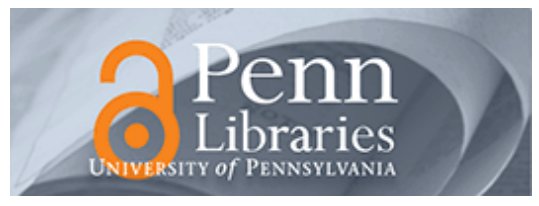

University of Pennsylvania

ScholarlyCommons

Marketing Papers

Wharton Faculty Research

5-1-1996

\title{
Competitor Orientation: Effects of Objectives and Information on Managerial Decisions and Profitability
}

\author{
J. Scott Armstrong \\ University of Pennsylvania, armstrong@wharton.upenn.edu \\ Fred Collopy \\ Case Western Reserve University
}

Follow this and additional works at: https://repository.upenn.edu/marketing_papers

Part of the Marketing Commons

\section{Recommended Citation}

Armstrong, J. S., \& Collopy, F. (1996). Competitor Orientation: Effects of Objectives and Information on Managerial Decisions and Profitability. Retrieved from https://repository.upenn.edu/marketing_papers/ 120

Postprint version. Published in Journal of Marketing Research, Volume 33, Issue 2, May 1996, pages 188-199.

Publisher URL: http://www.ama.org/pubs/jmr/index.html

This paper is posted at ScholarlyCommons. https://repository.upenn.edu/marketing_papers/120

For more information, please contact repository@pobox.upenn.edu. 


\title{
Competitor Orientation: Effects of Objectives and Information on Managerial Decisions and Profitability
}

\author{
Abstract \\ We examine how competitor-oriented objectives and the availability of competitor oriented information \\ can affect managerial decisions and the profitability of firms. Using a variety of evidence collected over \\ nine years, we compare the long-term profitability of competitor-oriented and self-oriented objectives. \\ Disciplines \\ Marketing \\ Comments \\ Postprint version. Published in Journal of Marketing Research, Volume 33, Issue 2, May 1996, pages \\ 188-199. \\ Publisher URL: http://www.ama.org/pubs/jmr/index.html
}


This paper is reprinted with permission from the Journal of Marketing Research, published by the American Marketing Association, J. Scott Armstrong, May 1996, Vol. 23, pp 188-199.

\section{Competitor Orientation: \\ Effects of Objectives and Information on Managerial Decisions and Profitability}

\section{J. Scott Armstrong and Fred Collopy ${ }^{1}$}

Traditional economic theory calls for firms to maximize shareholder wealth. However, managers often do not explicitly pursue the maximization of profits (Mueller 1992). Instead, they frequently make decisions so as to perform well relative to their competitors, which we refer to as having competitor-oriented objectives. Managers might choose not to focus on maximizing future profits, because profits are difficult to forecast or because a focus on profits may lead to a shortterm orientation at the expense of long-term considerations. Because it is difficult to determine how close a firm is to "maximum profits," managers may worry that using such a measure could make them or their organizations content with mediocre performance.

Some experts argue that if profits do not motivate managers effectively, relative measures, such as market share, should be used. Kotler (1988, p. 333) states that the strategic objective of many firms "is to increase their market shares, thinking that this will lead to greater profitability." Compared with profit maximizing, such competitor-oriented objectives may be more visible because the performance cf another firm serves as a benchmark. In the face of an uncertain future, market share can serve as an intermediate goal that positions the firm for long-term profitability.

Competitor-oriented objectives are advocated in textbooks, magazines, and journals. For example, Hendon (1986, p. 1) stresses beating competitors at the expense of all other objectives, including profit maximization. He states that "Business is war! . . . It is a zero sum game. . . . Military people want to destroy a target; business executives want to eliminate a competitor." Parks, Pharr, and Lockeman (1994, p. 68) say, "Just as in war, the reality of market-share battles is that the success of the victor depends upon the failure of the loser."

Over the past half-century, improvements in information systems have made competitororiented information-such as market share-more timely, accurate, detailed, and cost-effective,

${ }^{1}$ J. Scott Armstrong is Associate Professor of Marketing, the Wharton School, University of Pennsylvania. Fred Collopy is Assistant Professor of Management Information and Decision Systems, the Weatherhead School of Management, Case Western Reserve University. Robert H. Colgrove assisted in the problem formulation and data collection for the laboratory experiment. Richard H. Franke was especially helpful in guiding our thinking. Jonlee Andrews, Hector Bogo, Richard J. Boland, Gregory S. Carpenter, Douglas Cowherd, George Day, Peter R. Dickson, Jehoshua Eliashberg, Peter Fader, John U. Farley, Robert Fildes, James W. Genti. David E. Griffith, Robin Hogarth, Graham Hooley, Raymond Hubbard, Aron Katsenelinboigen, Edwin A. Locke, Sharon McCarthy, Shelby McIntyre, Glen Omura, John Roberts, William Ross, Stephen C. Sanders, Steven P. Schnaars, Ulrike Schultze, Warren Thorngate, U. N. Umesh, Joel E. Urbany, Eric Waarts, Molly Watson, Dick R. Wittink, J. Thomas Yokum, and anonymous JMR reviewers provided useful comments. Jennifer L. Armstrong, Suzanne Berman, Gina Bloom, Mary Haight, Vanessa Lacoss, Martha Lightwood, and Phan Lam provided editorial assistance. The authors thank the Strategic Management Group (Philadelphia) and IDEA (Buenos Aires) for their cooperation, and the Huntsman Center at the Wharton School, which provided partial funding. 
thus making it easier to pursue competitor-oriented objectives. One recent development is the use of scanner data. Some experts, for example, consider that the goal of using scanner data is to "take market share away from the other guy.",

We examine how competitor-oriented objectives and the availability of competitororiented information can affect managerial decisions and the profitability of firms. Using a variety of evidence collected over nine years, we compare the long-term profitability of competitororiented and self-oriented objectives.

\section{Students' and Managers' Beliefs About Competitor-Oriented Objectives}

Textbooks and experts advocate the use of competitor-oriented objectives-but this would not matter if their advice were ignored. To determine whether these views are held by faculty, students, and managers, we conducted a series of convenience surveys.

In surveys of marketing faculty and students in 1992, we asked: "What do you believe would be the effects on long-term profitability if a firm has as its primary goal to achieve higher market share?"' Of the 102 respondents, 57\% believed that profits would be higher, $27 \%$ believed that they would be lower, and $16 \%$ were undecided.

Between 1989 and 1994, we asked 170 Masters of Business Administration (MBA) students whether "the primary purpose of the firm is (a) to do better than its competitors, or (b) to do the best that it can." One-third of these students believed that the primary purpose of the firm is to do better than its competitors. About the same number agreed with the statement that "the best way to judge the success of a firm is by how well it does relative to its competitors." In early 1995, we asked the same questions of 54 students at a university in Korea; $39 \%$ and $41 \%$, respectively, agreed with these statements. ${ }^{4}$

Many managers believe that their firms use competitor-oriented objectives. In 1993, we surveyed 72 managers from a variety of firms who were attending seminars in Cleveland, Buenos Aires, and Santiago. Half of the respondents agreed that "the primary purpose of our firm is to be better than its competitors." Thirty-nine percent agreed that "the best way to judge the success of our firm is by how well it does relative to our competitors."

To examine further whether managers use competitor-oriented objectives, we examined Japan, where experts (e.g., Abegglen and Stalk 1985) claim that competitor-oriented objectives are common. Only $29 \%$ of senior executives from Japanese companies $(n=21)$ said that the primary purpose of their firms is to be better than their competitors, and $48 \%$ judged their success by how well they do relative to their competitors. ${ }^{5}$ in 1992.

${ }^{2}$ Stated by James Andress, president of Information Resources in a speech at The Wharton School

${ }^{3}$ Respondents were marketing faculty and students at the European Marketing Association Conference in Aarhus, Denmark $(n=13)$, the University of Auckland $(n=12)$, the University of Canterbury $(n=53), 4$ the University of Otago $(n=24)$.

${ }^{4}$ Wujin Chu collected these survey responses.

${ }^{5}$ Hotaka Katahira conducted this survey. 
It appears, then, that many business professors, students, and managers believe that a competitor orientation is desirable and will enhance firm performance. This suggests that there are at least two competing viewpoints about the objectives of firms. The first is that managers should pursue profits as directly as possible, and the second is that managers should use competitororiented objectives (such as market share) as a path to long-term profits. In the subsequent section, we discuss our hypotheses and related research.

\section{Hypotheses and related research}

Studies using decisions in simple games suggest that some people adopt competitororiented objectives. Kuhlman and Marshello (1975) summarized research from three such studies. The share of people that selected competitor-oriented responses ranged from $21 \%$ to $49 \%$, depending on game instructions and payoffs. Liebrand and van Run (1985) found similar results across cultures.

Griesinger and Livingston (1973) concluded from a review of experimental game literature that the proportion of "competitive" subjects varies depending on personality, cultural factors, and situational factors, such as feedback and game instructions. They also concluded (p. 187) that many subjects "seemed eager to know what was expected of them in order that they might adopt an appropriate orientation to the game." For example, the results from laboratory studies by Deutsch $(1958,1960)$ imply that explicit support for competitor-oriented objectives has a strong effect.

We hypothesized that under certain conditions some managers adopt competitor-oriented objectives. We further hypothesized that when competitor-oriented objectives are adopted, profits are reduced. Note that these hypotheses deal with objectives, not strategies. It seems reasonable that decision makers should consider competitors' actions when developing strategies. For example, it might be useful to examine competitors' actions for idcas about design, price, and service. Also, managers should probably consider how competitors will react to their actions.

\section{Conditions Under Which Managers Adopt Competitor Oriented Objectives}

Social comparison theory (Suls 1977) suggests that under some conditions, people judge their performance relative to others. We expect that certain identifiable conditions might lead managers to act competitively, such as when information about competitors made available to them. Similarly, when managers use techniques that focus attention on their company's relative performance, they are more likely to seek to maximize the competitor-oriented measure of performance than the profits.

Availability of competitor-oriented information. Dollar-auction studies demonstrate competitor-oriented behavior when one has direct knowledge about the competitor's response. Subjects bid for a dollar, with a rule that only the top bidder wins, but the top two bidders must pay. Final bids by each of the top bidders are usually well in excess of a dollar. The primary motivation of these bidders is to prevent their competitor from winning. These studies have been replicated in many countries (Teger 1980).

The prisoner's dilemma has been widely used to examine decision making. Subjects can gain by defecting, but if both parties defect, they are worse off. In one such study, Corfman and Lehmann (1994) asked subjects to make "advertising spending decisions as marketing managers 
of a medium-sized manufacturer selling in mature markets" and to assume they were committed to remaining with the company for five years. The advertising decision involved high (competitive) or low (cooperative) budgets, and their 57 subjects chose high $78 \%$ of the time. Griffith and Rust (1994) compared the performance of subjects (MBA students) against normative pricing algorithms; their decision makers appeared to emphasize relative performance against competitors, even when they were explicitly instructed to maximize profits and their monetary compensation was based solely on profits.

One of the difficulties in assessing whether subjects are employing competitor-oriented objectives is that the desire to improve profit might explain some of the results. By revising the prisoner's dilemma payoff matrix, it is possible to remove the profit motive as an explanation. Scodel and colleagues (1959) used a matrix in which the payoff to a player does not vary when the other subject is cooperative. Each cell shows Player One's score followed by Player Two's:

Player Two

\begin{tabular}{lll}
\hline Player One & Black & Red \\
Black & 3.3 & 1.3 \\
Red & 3.1 & 0.0
\end{tabular}

Assume that players were profit maximizers. Player One would select black if he expected Player Two to select red, because he would earn one point rather than zero. He would be indifferent if he thought that Player Two would select black, earning 3 points either way. The matrix is symmetrical, so neither player should prefer red in either condition. Interestingly, the proportion of red-red decisions exceeded black-black for 20 of the 22 pairs of subjects tested by Scodel and colleagues (1959) in a multi-period experiment. In terms of profit maximizing, this behavior is irrational; it is rational, however, if the players have competitor-oriented objectives-only by selecting red does a player have a chance of doing better than the competitor.

Messick and Thorngate (1967) examined a payoff matrix in which subjects would lose money by making competitive decisions if the other player were cooperative:

\begin{tabular}{lll}
\multicolumn{3}{c}{ Player Two } \\
\hline Player One & Black & Red \\
Black & 8.8 & 1.2 \\
Red & 2.1 & 5.5
\end{tabular}

Subjects were instructed "to earn as much money for themselves as possible," and a monetary payoff, based on the number of points scored, was provided. The highest payoff comes when both play black. However, only by choosing red can one player do better than the other. When provided with feedback only on their own earnings, about one-third selected red, the competitive decision. When given feedback about other players' gains as well, most subjects selected red; on their last 20 decisions, almost 90 percent of these subjects' choices were red. 
These findings about the impact of competitive information in two-player games are robust. Messick and Thorngate (1967) and Messick and McClintock (1968) examined variations of the preceding payoff matrix. They concluded that subjects primarily wanted to avoid decisions in which their earnings might be less than their competitor's. Messick and McClintock (1968, p. 23) also concluded that "subjects receiving relative-score infonnation played to maximize the difference between their own and other player's scores more frequently than subjects given only [their] own ... scores."

In a quasi-experiment involving food stores in four U.S. cities, Boynton, Blake, and Uhl (1983) found that the publication of average food prices at various stores had little impact on consumer behavior. But it did lead stores to respond to one another such that the average prices dropped by approximately two percent. As a result, this competitive information reduced profits. Leeflang and Wittink (1996), in a study of seven large brands of a nondurable, nonfood products sold in the Netherlands, concluded that managers overreacted to each other's promotional activities. In a replication in New Zealand of the Leeflang and Wittink study, Brodie and Bonfrer (1996) found even stronger evidence that managers were too competitor oriented.

Application of competitor-oriented techniques. Many management techniques focus attention on market share. For example, portfolio planning methods examine performance relative to the competitors. Use of these methods seems to be detrimental to profits. In laboratory experiments with 1015 subjects, Armstrong and Brodie (1994) found that use of the Boston Consulting Group matrix as a decision aid substantially reduces the profitability of subjects' decisions. Slater and Zwirlein (1992) concluded from a study of 129 firms that those whose strategies are consistent with portfolio planning models have lower returns to shareholders. Capon, Farley, and Hulbert (1987, pp. 316-17) found that firms that use the Boston Consulting Group portfolio matrix methods report a lower return on capital than those not using them.

\section{Effects of Competitor-Oriented Objectives on Performance}

It is well established that objectives affect performance (Locke and Latham 1990). In particular, objectives have a strong effect when they are made explicit. These findings apply to groups as well as to individuals (O’Leary-Kelly, Martocchio, and Frank 1994).

When discussing the effects of a competitor orientation on performance, people often generalize from sports, war, and other areas. Yet, their conclusions may be suspect even in those areas. Kohn's (1986) review of competition contains 388 references drawn from a variety of areas, such as sports, education, and the performing arts (but not from business), He concluded that though there may be conditions under which competitor-oriented objectives improve performance, in general, they do not.

Campbell and Furrer (1995), in an experiment involving the solution of routine arithmetic problems, concluded that competition had "a significant dysfunctional effect on task performance." In Deutsch's $(1958,1960)$ studies, when participants were told to do better than their opponents, both parties ended up worse off than when told to do the best they could for themselves.

Market share is often used as a relative measure of performance, and it may be a surrogate for the measure of true interest, namely, long-term profit. Because it does not directly assess what is of interest, there is a potential for other factors to intervene, causing it to give a less accurate 
representation of the effects on profits. Moreover, basing decisions on attaining market share can have harmful effects, such as price wars. Cassady, who examined actual price wars, concluded that, in some situations, "vendors temporarily shift their emphasis away from attaining success [for themselves] and toward preventing the success of rivals" (summarized-by Teger 1980). Similarly, Anterasian and Graham (1989) found that detrimental performance resulted from competitor-oriented objectives. They used a simulation of firms to compare a self-oriented goal (stability) against a competitor-oriented goal (market share). The market share goal reduced profits when the market had cycles.

Szymanski, Bharadwaj, and Varadarajan (1993) conducted a meta-analysis of studies relating market share and profitability. These cross-sectional studies showed positive correlations between market share and profitability. Many observers have concluded that this relationship is causal, though others (e.g., Jacobson and Aaker 1985; Prescott, Kohli and Venkatraman 1986) disagree. For example, firms with profits as their sole objective might produce superior products and, as a result, achieve gains in both market share and profits. Moreover, and of critical importance to the issues raised here, these studies did not examine the objectives of the managers.

Studies that have used a longitudinal, rather than cross-sectional, approach have found a negative relationship between market share and profits. Anterasian and Graham (1989) analyzed data on 42 firms in industries that had cycles; companies that lost market share during growth periods tended to be more profitable over the cycle than firms in the same industry that gained market share. Tschoegl and Yu (1990), in a study of the liquor market, found that a high market share did not help in gaining further share and did not produce stability in the firm's sales. Montgomery and Wernerfelt (1991) examined the performance of six large U.S. brewers from 1969 to 1979 , a period characterized by large changes in market share; using returns on stocks, they concluded (p. 958) that gains in market share were associated with "the destruction, rather than the creation, of firm value."

\section{Laboratory experiments}

We conducted laboratory experiments to examine whether managers make competitororiented decisions even when they know in advance that such decisions are harmful to profits. The decisions of subjects who were given information only on their own firm's profits were compared with those of subjects who also were given information on their competitor's profits.

\section{Administration}

In the subsequent discussion, a "treatment" refers to the description provided to the subjects (e.g., "harm" or "beat"). These treatments were used to examine alternative explanations. Treatments were randomly assigned, and each subject received only one. An "administration" refers to the treatments tested at a given time. Some administrations had few subjects, so few treatments were used. After making their decisions, subjects responded to written follow-up questions about reasons for their decisions. Most administrations were concluded with a debriefing of the subjects.

\section{Subjects}


Managers or potential managers were sought as subjects. The subjects $(\mathrm{n}=1016)$ came from two major business schools in the United States (73 undergraduates, 846 MBAs, 42 executive MBAs) and from a business school in Argentina (20 MBAs, 35 executive MBAs).

The subjects were familiar with the type of problem presented, through either academic training or work experience. Almost all had full-time work experience, and their managerial experience was extensive. The experiments were conducted in classroom settings, and the subjects worked individually. This use of captive subjects reduced self-selection bias.

\section{Materials}

Subjects were asked to assume the role of a marketing manager for a company called Big Guys, Inc. (To avoid associations with actual firms, names that sounded obviously fictitious were used.) Subjects were told, "We are performing an experiment in decision-making and we need your help. . . . You will only need about 10 or 15 minutes to complete the experiment."

The subjects received written descriptions of a business situation that was more extreme than might be encountered in the real world. The decision involved a choice of a "high" or "low" price for a new product. Five-year profit forecasts were provided for each pricing decision. Our intent was to convey uncertainty about profits after the stated planning horizon. A base treatment made no mention of competitors:

You are the marketing manager of a manufacturing firm known as Big Guys, Inc. As the company's marketing manager, you are responsible for all marketing decisions and strategies, including the pricing structure of the firm's products. Recently your company introduced a new highly technical product, and you have been asked to set the pricing strategy for this product. You calculate the present value of the total profits expected for your firm over the next five years. You determine the following results for both strategies:

\begin{tabular}{cc} 
Expected Profits Over Five Years \\
\hline Low-Price Strategy & High-Price Strategy \\
$\$ 40$ million & $\$ 80$ million
\end{tabular}

The harm and beat treatments added information about the impact of the subjects' decisions on competitors.

Harm treatment. In this treatment, subjects were able to harm their competitors. Subjects were told that their main competitor had a similar product and that the market for both products was the same. The following was added to their description:

You are aware that your main competitor, Other Guys, Inc., intends to introduce a product that is very similar to the one that your firm has just introduced. You should assume that the competitor's product is as good as yours in every way that is important to the market, and the market is the same for both products. Therefore, the pricing strategy which you must formulate for your product should take into account this competitive force.

You are essentially faced with two choices: 
1. Keep your price low, which causes your competition to suffer a substantial loss, or 2. Choose a higher price that produces higher profits for your firm, but which also allows the competition to prosper.

You then calculate the present value of the total profits expected for your firm over the next five years, as well as for the competitors (Other Guys). You note that after five years the products are in the mature stage of the product life cycle. You determine the following results for the two strategies:

\begin{tabular}{lcc} 
& \multicolumn{3}{c}{ Expected Profits Over Five Years } \\
\hline & Low- Price Strategy & High-Price Strategy \\
Big Guys & $\$ 40$ million & $\$ 80$ million \\
Other Guys & -100 million & 40 million
\end{tabular}

Subjects could earn $\$ 140$ million more than competitors by choosing the low price, but only $\$ 40$ million more by choosing the high price. In terms of relative gains, then, the low price is best.

Beat treatment. Because the harm treatment inflicts heavy losses, subjects might infer that this leads to the demise of the competitor and discourages future entry. If some subjects were simply making judgments they believed would lead to long-term profits, then the elimination of this damage to the competitor might reduce the number making this choice. The beat treatment addresses this.

The description was similar to the harm treatment. Outcomes for the subject's firm were the same as in the harm treatment, but the competitor's profits were $\$ 120$ million higher for each alternative. At the low price, the subjects' firm earns \$20 million more in profits than the competitor, but the competitor apparently operates successfully. Profits are higher for the highprice decision, but here the competitor earns more than the subject's firm. Thus, only by choosing the lower price can the subject do better than the competitor, whereas in the harm treatment the firm would "win" with either strategy.

Expected Profits Over Five Years

\begin{tabular}{lcc}
\hline & Low- Price Strategy & High-Price Strategy \\
Big Guys & $\$ 40$ million & $\$ 80$ million \\
Other Guys & 20 million & 160 million
\end{tabular}

\section{Face Validity of the Instruments}

To assess whether the situations allowed for profit maximization, they were presented to economics and finance professors at a major university suggested by the chair of the economics department on the basis of relevant experience. Each faculty member received the harm and beat treatments and was asked to assume that he (all faculty members were male) had been called in as an economic advisor to the firm. Six faculty members responded, and all agreed that the high price was the profit-maximizing decision for each treatment; when asked, they expressed no need for further information. 


\section{Base Results}

When no information was provided about the performance of competitors, $14 \%$ of 65 subjects selected the less profitable decision. On the follow-up questionnaire, some subjects who had selected the low price expressed concern about their competitors.

In the harm treatment, $34 \%$ of the 139 subjects selected the less profitable decision. Thus, here subjects were twice as likely to select the less profitable decision as when no information was provided about competitors $(\mathrm{Z}=2.66 ; p<.01)$.

In the beat treatment, $60 \%$ of the 60 subjects selected the low price. Testing against the null hypothesis that the information about competitor's performance had no effect (the beat treatment versus the base treatment with no information about competitors) produced a significant rejection $(\mathrm{Z}=5.86 ; p<.01)$.

\section{Replications with Extensions}

To assess reliability and address threats to validity, 23 different treatments using 43 experimental administrations were conducted from 1986 to early 1995 . One concern in these extensions was to assess the alternative explanation that subjects selected the low-price decision so as to maximize long-term profits. These extensions involved treatments that lengthened the time horizon, changed the situation from the future to the past, and equalized the final market values. ${ }^{6}$

Lengthening time horizon. Because subjects might be willing to suffer short-term losses in exchange for long-term gains, the time horizon was lengthened from 5 to 20 years for the harm and beat treatments. ${ }^{7}$ Subjects were told that the matrix represented net present values of profits over a 20 -year period. For the 42 subjects who did not receive information about the performance of their competitor in the pricing treatment, $12 \%$ made the less profitable decision. In contrast, $45 \%$ of the 40 harm treatment subjects and $30 \%$ of the 40 beat treatment subjects selected the less profitable decision. The difference between the subjects with and without information on competitors was significant for both the harm $(\mathrm{Z}=3.02 ; p<.01)$ and beat treatments $(\mathrm{Z}=1.65 ; p$ $<.05)$. Lengthening the horizon had little effect on results in the harm treatment, but it reduced

\footnotetext{
${ }^{6}$ Minor extensions examined the nature of the product. The problem was initially described as involving a "new, highly technical product." To assess whether the type of product made a difference, the product was varied in treatments that did not mention competitors. One treatment, administered to 15 subjects, specified no product; here, only one subject chose the less profitable decision. Another treatment said that the product was "a new perfume for women;" three of 17 subjects chose the less profitable decision. For these two treatments, then, $12.5 \%$ of the 32 subjects chose the less profitable product. This is similar to the $13.3 \%$ of the 75 subjects who had received the technical product treatment. We concluded that the type of product did not have an important effect and have combined all these results in the analysis of the base treatment.

${ }^{7}$ This change was also made for the ex post pricing decisions that are described in the next section.
} 
the percentage choosing the low-price strategy in the beat treatment; we have no explanation for this result.

Ex post pricing decision. Despite the instructions, subjects might have made different assumptions about profits beyond the stated planning horizon. To control for this, the problem was changed to refer to the past. Here, subjects had to decide which of two brand managers should be promoted by the company, called Multiple Products, Inc. In this "ex post pricing decision," the choices were between a manager who used a high-price strategy and one who used a low price strategy. Both had managed in comparable but independent geographical regions for the same five years. The profit matrix was identical with that in the original harm pricing decision: The manager choosing the high price earned high profits and his competitor also earned high profits, whereas the manager choosing the low price earned lower profits and his competitor's profits were negative. The description stated that "whatever their profit situation has been over the past five years, all of the competitors still exist in their respective regions."

Of the 76 subjects in the ex post harm pricing treatment, $40 \%$ promoted the marketing manager who used the low price. Of the 127 subjects in these same administrations who had received the basic harm pricing treatment, 34\% selected the less profitable decision. Thus, these results are not consistent with a hypothesis that the subjects were trying to increase long-term profits.

Similarly, of the 69 subjects in an ex post beat treatment, $51 \%$ promoted the manager who used the low-price strategy. This is comparable to the $60 \%$ of the subjects who selected the lowprofit decision in the basic beat treatment in the same administrations.

Equalizing final market values. A further revision of the ex post pricing treatments added information that the final market values of the company's two divisions were the same:

Currently, the firm has a cash flow shortage. Over the past seven years the firm has maintained its dividend payout in the face of declining profits, such that all profits have been paid out. As a result, the firm has decided to sell one, but not both, divisions. In trying to decide which division to sell, both were put on the market. Bidding has been intense and the selling price for each division is almost identical. These have been good divisions for the company. They had been acquired ten years ago and the purchase price for each was $40 \%$ of the current market price. Marketing for the two divisions are headed by Harry Jones and Louie Smith. You must decide whether to retain Harry or Louie for the division that the company will keep.

In other words, the two divisions were valued equally initially and also currently, but the manager who used the high price achieved much higher profits during the intervening period.

Of the 87 subjects receiving the equal-market-value harm treatment, 52\% promoted the manager who had the lower profits. Surprisingly, this exceeded the $34 \%$ of such promotions by the 80 subjects in the equal-market-value beat treatment. Given complete information about profitability, then, $43 \%$ of the 167 subjects selected the competitor-oriented (less profitable) option.

Exposure to Competitor-Oriented Techniques 
We anticipated that competitiveness would intensify when people were exposed to techniques that advocate competitor-oriented objectives. To test this, some subjects were provided with a description of the experience curve, which states that reductions in unit costs occur as cumulative volume increases. The experience curve strategy advises firms to cut prices to build volume, in order to propel the firm down its cost curve faster than competitors can move down theirs. In other words, they should price so as to prevent competitors from catching up. Lieberman (1987, p. 451) concluded that the experience curve produces incentives that "often intensify competition and reduce profits."

To assess the impact of exposure to the experience curve, some subjects received a description from Kiechel (1981, pp. 139 - 140) advocating its use. The decisions of those 97 subjects were compared with those from 137 control subjects in the same administrations; the latter received no information about the experience curve. More experience curve subjects selected the less profitable decision than did control subjects $(59 \%$ versus $45 \% ; p<.05$ using chisquare).

A neutral description of the experience curve from Porter (1980) was provided to another set of subjects. Of the 63 subjects receiving this description, $41 \%$ selected the less profitable decision, and $42 \%$ of the 86 control subjects selected it. By this test, the neutral description of the experience curve had no significant effect.

In a before-and-after design, 113 subjects made decisions before reading the neutral description of the experience curve. Then they read it and made a second decision. Nine subjects changed from a high to a low price decision, and none went in the other direction. The percentage who chose the lower-profit choice went from $43 \%$ to $51 \%$. This was a modest but statistically significant increase $(\mathrm{p}<.05$ based on the McNemar change test with correction for continuity from Siegel and Casteilan 1988).

Overall, then, information about the experience curve produced less profitable decisions for two tests, with no difference on one. This provides moderate support for our hypothesis.

\section{Management Training}

Management training often emphasizes competing. For subjects from one of the U.S. business schools, decisions made by those who had more formal management education were compared with decisions by subjects who had less. Subjects just entering the management program were placed in a "low" group, those who had had courses in strategic planning were put in a "high" group, and the rest were placed in an "intermediate" group. This classification was rough, because subjects within each group differed with respect to their prior management education and the treatments were not balanced across education levels. Furthermore, the competitor orientation was probably high among most subjects prior to this management program. These shortcomings should reduce the estimated effect of education on decisions.

Using decisions by subjects in the harm and beat treatments, education levels were compared. Of the 236 subjects in the low education group, $38 \%$ selected the less profitable decision. In contrast, $46 \%$ of the 227 subjects in the intermediate education group and $55 \%$ of the 88 subjects in the high education group chose the less profitable decision. The differences among groups were statistically significant ( $p<.05$ using chi-square). In effect then, those with more management education made less profitable decisions. 


\section{Follow-Up Questionnaire}

In follow-up questionnaires from 14 administrations of the experiment, subjects were asked, "Why did you make this decision?" In general, once subjects took the competitor's performance into account, they were less likely to pay attention to their own profits. Eighty-three percent of the 107 subjects who mentioned competitors selected the less profitable decision.

Sixty-seven percent of the 133 subjects who selected the low-price decision made statements about beating their competitors, while only $38 \%$ discussed profits. Some of those selecting the low price said that the company's objective was to increase market share, that it was important to beat competitors, or that they wanted to be the leader. Some respondents commented on their willingness to sacrifice profits. One respondent who had been employed by an international consulting firm stated, "Perhaps it's my strategic planning background, but I would definitely pay to harm my competitors." Another subject who selected the less profitable decision said, "Louie's strategy [low price, competitor-oriented] has generated twice the profits of the competitor, while Harry's strategy [high price] has reaped half the profits of the competitor. Hence, Louie's strategy seems to be the strongest. Destroy the competitor."

Of the 208 subjects selecting the high-price decision, $78 \%$ explicitly discussed profits, while fewer than $10 \%$ mentioned competitors. Of the latter, most said that they did not want to harm their competitor. Some said that they were pleased that their competitor would also succeed ("a win-win situation"). Others stated that the competitor's performance was not relevant to their decision.

\section{Limitations and Threats to Validity of the Laboratory Studies}

The use of students as subjects posed few threats to the studies' validity. Prior research, summarized by Ashton and Kramer (1980), found similarity between students and non-students in studies of decision making, which is the concern of our study. Also, consistent with criteria suggested in Gordon, Slade, and Schmitt (1987), our subjects were similar to the population of interest. Corfman and Lehmann (1994) found no substantial differences between executives and students in their prisoner's dilemma study of advertising decisions. Results from the experience curve treatment might be due to demand effects. Providing information about the experience curve might have led subjects to assume that it was a relevant technique, but it is difficult to use demand effects to explain the differences in decisions across levels of education. In the other

Table 1

Percentage of Subjects who Selected the Less Profitable Decision

(Number of Subjects)

\begin{tabular}{lccc}
\hline & \multicolumn{3}{c}{ Information About Competitors } \\
\cline { 2 - 4 } \multicolumn{1}{c}{ Treatment } & None & Harm & Beat \\
\hline Pricing: & & & \\
5 years (benchmark) & $14(65)$ & $34(139)^{* *}$ & $60(60)^{* *}$ \\
20 years & $12(42)$ & $45(40)^{* *}$ & $30(40)^{*}$ \\
\hline
\end{tabular}


Ex Post Pricing:

5 years

20 years

5 years: equal value

Unweighted averages

$$
\text { n.a. } \dagger
$$

n.a.

n.a.
51(69)

30(30)

34(80)

38

* Significant at $p<.05$ with one-tail t-tests (compared with results from "none" column).

$* *$ Significant at $p<.01$.

$\dagger$ No tests could be conducted for the ex post treatments, because we could not construct a "no information" version.

parts of the experiments, we had no reason to expect demand effects. We did consider the possibility that subjects might answer so as to look good to the experimenter (Sigall, Aronson, and van House 1970). To do this successfully, they would have had to be aware of the purpose of the study. Follow-up discussions with subjects revealed some awareness. When 84 of them were asked to guess the purpose, ten (12\%) guessed correctly. Only a small percentage, then, would have known how to modify their responses to look good in this situation. Nevertheless, this does not rule out demand effects (Shimp, Hyatt, and Snyder 1991).

Although researchers in management have become increasingly critical of the external validity of laboratory studies (Griffin and Kacmar 1991), evidence suggests that their validity is comparable to that of field experiments (Locke 1986).

\section{Summary of Laboratory Results}

The results, summarized in Table 1, were consistent with our hypotheses, the effects were strong, and they were statistically significant: A substantial portion of the subjects selected competitor-oriented decisions. This provides evidence of economically irrational behavior.

\section{Field Study}

Historical performance of American industrial firms between 1938 and 1994 was used to determine the extent to which a competitor orientation can affect profitability. To assess what marketing experts would expect from such a study, we posed the following question to convenience samples of 90 marketing faculty members in New Zealand and the United States, as well as to 18 managers in Buenos Aires:

What if we ran the following study: (1) select 20 firms from different industries; (2) assess the extent to which their goals are competitor oriented (market share); and (3) examine their profits over the next three decades. Assuming that the 20 firms would differ greatly with respect to competitor orientation, what would you predict? 
The key item was: "Profits in firms with market share as a primary goal are (I) much less, (2) less, (3) the same, (4) more, or (5) much more than in firms with profit-oriented goals." Of the 108 respondents, $52 \%$ said that profits would be more or much more, and $26 \%$ thought they would be less or much less.

Information about firms' competitor orientations and their long-term profitability was needed to test the relationship. Fortunately, information on pricing objectives of 20 large U.S. companies had been collected by Lanzillotti (1958), who, sponsored by the Brookings Institution, investigated the price-setting process. He examined "the motivational hypothesis of the firm, i.e., the specific objectives upon which business firms base pricing decisions."

\section{Competitor Orientation of 20 Firms}

The 20 corporations, drawn from a variety of industries, were among the 200 largest U.S. industrial corporations in terms of assets. According to Lanzillotti (1958, p. 921 - 22), "The companies were selected from among the largest corporations on the basis of the willingness of management to cooperate by permitting extensive interviews with top company officials," and because "the prominence of each of the corporations in their respective industries made them masters, to a significant degree, of their fates; hence they were able to adjust pricing to the company's general goal."

The competitor orientation of the firms' objectives was inferred from Lanzillotti's description of their stated pricing policies. Between 1948 and 1951, he conducted interviews with company officials that lasted approximately one week in each company. Lanzillotti (1958) explained that such a careful procedure was needed because of the sensitive nature of pricing policies. A second set of interviews was carried out in 1956 - 1957 to fill gaps in the study and determine whether changes had occurred in pricing policies since the original interviews (Kaplan, Dirlam, and Lanzillotti 1958). Judging from Kaplan, Dirlam, and Lanzillotti's (p. 187) study, the competitor orientations were stable from the initial interviews to the follow-up interviews, a period of nine years. They also said that, in some firms, objectives were based on long-standing policies. For example, as far back as 1937 , A\&P had stated that their primary aim in pricing was to achieve a larger market share.

An 11-point scale ( $1=$ to do well for themselves; $11=$ to do well relative to competitors) was developed to assess firms' objectives. The objective of doing well for a person's own firm was identified by the presence of an explicitly stated pricing goal to maximize or increase profits. When profit targets were stated, a distinction was made between high and modest objectives. A priori, we classified a target as "high" if it called for maximizing profits or if it had a target return on investment (ROI) of at least $15 \%$ after taxes. At the other end of the scale were competitororiented objectives, stated in terms of market share. Goals of increasing or maximizing market share were classified as highly competitor orientated, and goals of maintaining market share were

Table 2

Objectives Scale and Number of Firms at each level

\begin{tabular}{llcl}
\hline Competitor & & \multicolumn{3}{c}{ Pricing Objectives } \\
Orientation \\
\cline { 2 - 4 } $\begin{array}{l}1=\text { low } \\
11=\text { high }\end{array}$ & Primary & Secondary & Number of Firms \\
\hline
\end{tabular}




\begin{tabular}{lccc}
1 & High Profit* & n.s. $\dagger$ & 3 \\
2 & Profit & n.s. & 1 \\
3 & Stability & n.s. & 1 \\
4 & High Profit & Maintain MS & 2 \\
5 & High Profit & Increase MS & 0 \\
6 & Profit & Maintain MS & 4 \\
7 & Profit & Increase MS & 0 \\
8 & Maintain MS & Profit & 2 \\
9 & Increase MS & Profit & 1 \\
10 & Maintain MS & n.s. & 4 \\
11 & Increase MS & n.s. & 2 \\
\hline
\end{tabular}

*High profit means a return of investment of at least $15 \%$ after taxes;

MS = market share.

n.s. $\dagger=$ "none stated."

moderately competitor oriented. Upper limits on market share (e.g., to stay under 20\%) were not coded as competitor oriented. Lanzillotti (1958) described "primary pricing goals," which were used to make basic category assignments, and "collateral pricing goals" (see Table 2). One firm did not specify objectives in terms of market share or profits, but focused on stability of operations. To handle this, an additional category was created between goals that focused only on profit and those that focused on market share.

Firms' orientations were coded by the first author and an expert on competitor-oriented behavior (Peter S. Fader). The latter received Lanzillotti's article (from which information about profitability and market share had been deleted) along with a copy of the rating scales. Intercoder reliability was high $(r=.96)$; minor differences occurred for orientations of only four firms.

Differences resulted from failures to describe how to handle an upper limit on market share and from the interpretation of Lanzillotti's description. After discussion, but before analyzing relationships, each coder changed two items; this produced full agreement.

Firms were located at all levels of the scale except 5 and 7. The median firm's orientation was 6, the scale's midpoint. Competitor-oriented objectives were adapted by $30 \%$, and an additional $45 \%$ used a combination of profit- and competitor-oriented objectives.

\section{Performance of the 20 Firms}

Our hypothesis states that a competitor orientation harms the firm's profit; it makes no prediction about relative performance. Thus, the company's profits were examined in absolute terms, not in comparison with others in \&e same industry. Specifically, the average after-tax ROI was used. Lanzillotti (1958) provided these data over nine years (1947-1955) because, in his opinion, they measured performance that might have been affected by the pricing policies. 
Return on investment was "net income to surplus" (after taxes) divided by the firm's "total assets." Restated earnings were used when available. To guard against errors, two research assistants independently collected the data, and the first author checked a sample of firms. ${ }^{8}$ (Our figures for ROI for 1947 - 1955, obtained from Moody's Industrial Manual, were somewhat different from those reported by Lanzillotti and we were unable to identify why. ${ }^{9}$ )

Competitor-oriented objectives and ROIs were negatively correlated for the $1947-1955$ data. The Spearman correlation (all reported correlations were corrected for ties) was $r_{s}=-.43$, which was statistically different from the null hypothesis that competitor-oriented objectives are not related to the level of profitability ( $\mathrm{p}=.03$ using a one-tail test). Because many other factors also influence a firm's ROI, these results suggest a strong relationship.

This analysis of profitability covered the period coincident with Lanzillotti's assessment of pricing goals, and we also analyzed the nine years after this. In Table 3, we present the ROI for each firm for 1956 - 1964. The Spearman correlation between competitor-orientation and ROI remained negative $\left(\mathrm{r}_{\mathrm{s}}=-.37\right)$ and statistically significant $(\mathrm{p}=.05)$-that is, firms that had competitor-oriented objectives in the 1950s continued to earn less on their investments.

Advocates of competitor-oriented objectives suggest that gaining market share improves long-term profitability, so we analyzed additional nine-year periods (see Table 3). The ROIs for 1965 - 1973 were based on Moody's Industrial Manual and those for 1974 - 1982 on Compustat ${ }^{10}$. As before, competitor-oriented objectives were inversely related to ROI - Spearman correlations were -.43 and -.45 respectively (both significant at $p<.05$ ).

We also looked at survival rates of the 20 companies. Survival was defined here as avoiding bankruptcy or sale of the firm because of poor performance. Companies whose only goal was profit (those coded as 1 or 2 in Table 3 ) were compared against those with market share as their only goal (codings of 10 or 11). Information from Moody's Industrial Manual through 1994 was examined, a span of 36 years since Lanzillotti's paper. All four profit-oriented firms survived, while four of the six competitor-oriented companies failed. ${ }^{11}$ Thus, competitor-oriented firms were less likely to survive ( $\mathrm{p}=.07$ by the Fisher Exact Test).

\section{Limitations of the Field Study}

\footnotetext{
${ }^{8}$ Jennifer L. Armstrong, Michael Halperin, and Gina Bloom collected financial data for the field study.

${ }^{9}$ Using Lanzillotti's data, the results would have been even stronger.

${ }^{10}$ Compustat was used because it was available for 1974 - 1982, and it adjusted these data to aid comparability across companies, thereby aiding potential replication. The figures for Moody's and Compustat were identical for about two-thirds of the entries for 1974 - 1982, and the differences were typically minor for the remaining one-third. When the 1974 - 1984 Moody's data were substituted, a Spearman correlation with competitor orientation of -.36 (significant at $\mathrm{p}=.06$, one-tail test) was obtained.

${ }^{11}$ Each of the failed firms experienced financial difficulties. As a result, Gulf was purchased by Chevron in 1985, American Can became Primerica in 1987 and abandoned the canning business, Swift reorganized with part becoming Esmark in 1973, and National Steel reorganized in 1983 under National Intergroup (a pharmaceutical company) and was bought by Japan's NKK Corporation.
} 
A person might argue with Lanzillotti's statement that these firms were masters of their fate, suggesting that short term conditions within the industry led firms to adopt competitororiented objectives. In particular, managers in firms that were doing poorly in the mid-1950s might have decided at that time that they could improve by focusing on market share. To test this, we examined the prior nine-year period (1938 - 1946; see Table 3). If a change in performance caused the change in orientation, there should be little correlation between competitor orientation and ROI in the earlier period. As it turned out, competitor orientation was negatively related to ROI (Spearman correlation $=-.54 ; p<.02)$.

Table 3

Competitor orientation of firms and ROI for nine-year periods

\begin{tabular}{|c|c|c|c|c|c|c|}
\hline \multirow[b]{2}{*}{ Firm } & \multirow{2}{*}{$\begin{array}{c}\text { Competitor } \\
\text { Orientation }\end{array}$} & \multicolumn{5}{|c|}{ ROI (After Taxes) } \\
\hline & & $\begin{array}{c}1938- \\
1946\end{array}$ & $\begin{array}{c}1947- \\
1955\end{array}$ & $\begin{array}{c}1956- \\
1964\end{array}$ & $\begin{array}{c}1965- \\
1973\end{array}$ & $\begin{array}{r}1974- \\
1982\end{array}$ \\
\hline DuPont & 1 & 9.1 & 15.4 & 15.5 & 8.0 & 6.9 \\
\hline General Electric & 1 & 8.1 & 10.9 & 9.4 & 6.7 & 7.9 \\
\hline Union Carbide & 1 & 9.8 & 11.0 & 9.1 & 6.3 & 6.6 \\
\hline Alcoa & 2 & 8.5 & 6.4 & 4.2 & 4.2 & 5.5 \\
\hline Kennecott & 3 & 8.6 & 13.3 & 8.9 & 8.2 & $3.2^{\mathrm{a}}$ \\
\hline General Motors & 4 & 8.8 & 16.6 & 13.2 & 12.0 & 6.3 \\
\hline Johns Manville & 4 & 6.8 & 11.2 & 4.6 & 7.6 & $4.9^{b}$ \\
\hline Standard Oil of New Jersey (Exxon ${ }^{c}$ ) & 6 & 5.4 & 13.0 & 7.8 & 7.6 & 8.0 \\
\hline General Foods & 6 & 11.9 & 8.2 & 11.4 & 8.9 & 7.4 \\
\hline US Steel (USX d ${ }^{\mathrm{d}}$ & 6 & 3.4 & 6.5 & 6.0 & 3.5 & 3.4 \\
\hline International Harvester ${ }^{\mathrm{e}}$ & 6 & 4.7 & 6.7 & 4.6 & 4.0 & $\& 3.4$ \\
\hline Kroger & 8 & 7.2 & 8.0 & 6.1 & 4.9 & 4.6 \\
\hline Standard Oil of Indiana ${ }^{f}$ & 8 & 5.3 & 7.1 & 5.4 & 6.4 & 8.3 \\
\hline Sears & 9 & 8.8 & 12.4 & 8.5 & 6.4 & 4.2 \\
\hline Goodyear & 10 & 5.8 & 6.4 & 7.0 & 5.7 & 4.0 \\
\hline Gulf $^{\mathrm{g}}$ & 10 & 5.0 & 9.7 & 8.9 & 7.1 & 6.3 \\
\hline American Can ${ }^{\mathrm{h}}$ & 10 & 6.8 & 7.8 & 5.2 & 4.8 & 3.8 \\
\hline Swift & 10 & 3.9 & 4.6 & 2.4 & 3.3 & n.a. ${ }^{\mathrm{i}}$ \\
\hline
\end{tabular}




\begin{tabular}{|c|c|c|c|c|c|c|}
\hline Great Atlantic \& Pacific & 11 & 6.8 & 8.4 & 7.8 & 4.2 & $\& 2.9$ \\
\hline National Steel & 11 & 5.2 & 9.6 & 6.0 & 5.1 & $1.1^{\mathrm{j}}$ \\
\hline $\begin{array}{l}\text { Correlation with } \\
\text { Competitor Orientation }\end{array}$ & & $\& 54^{*}$ & $\& 43^{*}$ & $\& 37 *$ & $\& 43^{*}$ & $\& 45^{*}$ \\
\hline
\end{tabular}

$*$ Correlations were significantly different from $\mathrm{r}=0$ at $p<.05$.

${ }^{a}$ Acquired by Standard Oil of Ohio in July 1981 (1981 - 82 excluded).

${ }^{\mathrm{b}}$ Succeeded by Manville Corporation on October 30, 1981, when the firm filed for Chapter 11 (1982 excluded).

${ }^{\mathrm{c}}$ Name changed in 1973.

${ }^{\mathrm{d}}$ Name changed in 1986.

${ }^{\mathrm{e}}$ Name changed to Navistar in 1986 and most assets were sold.

${ }^{\mathrm{f}}$ Name changed to Amoco in 1985.

${ }^{g}$ Acquired by Chevron in 1984.

${ }^{\mathrm{h}}$ Became part of Primerica, an insurance and financial firm, in 1987.

${ }^{\mathrm{i}}$ Reorganized April 30, 1973, after which Swift consisted only of food divisions (1973 and subsequent years excluded). Corporation.

${ }^{j}$ Reorganized as National Intergroup in 1982, and the steel operations were sold to Japan's NKK

Our analysis covered 54 years, and many changes occurred in the industries as well as in the firms. Of particular concern is that objectives of some firms might have changed. Such changes would be expected to reduce the relationship that we hypothesized. ${ }^{12}$ Another change is that some of the firms, such as Alcoa and DuPont, have decentralized and allowed the strategic business units to set their own objectives. Finally, differences among firms might have been caused by some other factor that happened to be related to the selection of this group of firms, but we were unable to think of such a factor.

\section{Discussion}

Our research strategy was one of triangulation: We proposed two hypotheses supported by prior research and then conducted a series of laboratory experiments and a field study. ${ }^{13}$ Several different measures and procedures were used, and these were established prior to analyzing the data. The studies utilized evidence from different cultures and different time periods. This multi-method, multi-measure strategy, articulated by Campbell and Fiske (1959), has been recommended where experiments with randomly selected subjects are difficult.

${ }^{12}$ For example, in December 1981, the Chief Executive Officer of General Electric (GE) publicly stated that GE's goal was to be number one or number two in each of its businesses (Slater 1993, pp. 73 76). This contrasts with GE's profit orientation in our analysis. It should be noted that GE also made other significant changes (e.g., downsizing and decentralization). The ROI in the decade prior to these changes was $7.5 \%$, whereas in the decade after it was $6.0 \%$. Many other factors varied over these two decades.

${ }^{13}$ We report on all but one of the studies that we undertook on this project. That study involved a comparison of managers' competitor orientation and the average market value of firms in a seven-year management game simulation. The results were consistent with our hypotheses $(\mathrm{p}<.10)$, but the test involved only four industries. Copies of these results are available to interested readers. 
What we find most striking, then, is the pattern of results. Although it is possible to provide alternative explanations for particular results, it is difficult to find an alternative that is consistent with the prior research and all our results.

On the other hand, various limitations have been identified in the previous research and our studies. Also, our results lack face validity among many experts. fn addition, there may be conditions under which competitor-oriented objectives are useful. That noted, Slater and Narver (1994) examined whether the competitive environment might have an impact on the effectiveness of different corporate objectives, but they found none.

Further studies should examine alternative explanations for our findings, limits to the generalizability of our conclusions, why competitor-oriented objectives are adopted, and the impact of competitor-oriented objectives on other stakeholders. Some experts, for example, suggest that customer satisfaction should be the focus of objective setting. We have not examined this, but it could be an area that warrants research.

\section{Summary and Conclusions}

In the laboratory study, information about their competitor's performance led more than $40 \%$ of subjects to select less-profitable alternatives. Replications and extensions were conducted so that 23 treatments were conducted in 43 experimental administrations with 1016 subjects over a nine-year period. Even when net present value of profits were reported for 20 years, more than one-third of the subjects chose the less profitable alternative. Another extension cast the problem in the past by asking which of two managers should be retained by the firm; almost $40 \%$ of the subjects decided to keep the manager that sacrificed his own firm's profits to do well relative to competitors. In an extension of this ex post pricing decision, which stated that the market values of the divisions were currently equal (such that the only thing that differed was the profit that had been earned by each manager), $43 \%$ of the subjects favored the manager who produced fewer profits. A competitor-oriented technique, the experience curve, led to less profitable decisions. Subjects with more management education (which presumably emphasizes competitor-oriented objectives) made less profitable decisions.

In the field study of 20 U.S. firms, those with competitor-oriented goals had lower ROIs during 1947 - 1955. Similar results were observed for each of three successive nine-year periods through 1982, as well. as for the nine-year period preceding 1947. Firms with competitor-oriented objectives were also less likely to survive.

Our results suggest that the use of competitor-oriented objectives is detrimental to profitability. Because of this pattern of evidence, we suggest that firms should ignore their competitors when setting objectives and, instead, focus directly on profit maximization. This conclusion has implications for managers and management professors. We recommend the following:

- Do not use market share as an objective.

- Avoid using sports and military analogies, because they foster a competitor orientation.

- If you use benchmarking, ensure that it does not influence objective setting.

- Do not use management science techniques that are oriented to maximizing market share, such as portfolio planning matrices and the experience curve. 
- Design information systems to focus attention on the firm's performance, as measured by profits.

Because of the evidence to date, we believe that microeconomic theory, with its emphasis on profit maximization, is the most sensible course of action, for firms; that is, managers should focus directly on profits. Our findings also raise concerns about information systems - having information about a competitor's performance may be harmful to a person's own performance. Improvements in the ability to measure market share, first through surveys and more recently through scanner data, might lead to a stronger focus on competitiveness and to less profitability.

\section{References}

Abegglen, James C. and G. Stalk, Jr. (1985), Kaisha: The Japanese Corporation. New York: Basic Books.

Anterasian, Cathy and J. L. Graham (1989), "When It's Good Management to Sacrifice MarketShare," Journal of Business Research, 19 (3), 187-213.

Armstrong, J. Scott and R. J. Brodie (1994), "Effects of Portfolio Planning Methods on DecisionMaking: Experimental Results," International Journal of Research in Marketing, 11 (1), 73-84.

Ashton, R. H. and S. S. Kramer (1980), "Students as Surrogates in Behavioral AccountingResearch: Some Evidence," Journal of Accounting Research, 18 (1), 1-16.

Boynton, Robert D., B. F. Blake, and J. N. Uhl (1983), "Retail Price Reporting Effects in Local Food Markets," American Journal of Agricultural Economics, 65 (1), 20-29.

Brodie, Roderick J. and A. Bonfrer (1996), “Do Managers Overreact to Each Others' Promotional Activity? Further Empirical Results," International Journal of Research in Marketing (forthcoming).

Campbell, Donald J. and D. W. Furrer (1995), "Goal Setting and Competition as Determinants of Task Performance," Journal of Organizational Behavior, 16 (4), 377 - 89.

Campbell, Donald T. and D. W. Fiske (1959), "Convergent and Discriminant Validation of the Multitrait-Multimethod Matrix,” Psychological Bulletin, 56 (2), 81-105.

Capon, N., J.U. Farley, and J. M. Hulbert (1987), Corporate Strategic Planning. New York: Columbia University Press.

Corfman, Kim P. and D. Lehmann (1994), "The Prisoner's Dilemma and the Role of Information in Setting Advertising Budgets," Journal of Advertising, 23 (2), 35-48.

Deutsch, Morton (1958), "Trust and Suspicion," Journal of Conflict Resolution, 2 (4), 265-279.

- (1960), "The Effect of Threat Upon Interpersonal Bargaining," Journal of Abnormal and Social Psychology, 61 (2), 181- 89.

Gordon, Michael L., Allen Slade, and N. Schmitt (1987), "Student Guinea Pigs: Porcine Predictors and Particularistic Phennmena," Academy of Management Review, 12 (1), 160 63.

Griesinger, Donald W. and J. W. Livingston, Jr. (1973), "Toward a Model of Interpersonal Motivation in Experimental Games," Behavioral Science, 18 (3), 173 - 88.

Griffin, Ricky and K. M. Kacmar (1991), "Laboratory Research in Management: Misconceptions and Missed Opportunities," Journal of Organizational Behavior, 12 (4), 301-11. 
Griffith, David E. and R. T. Rust (1994), "The Price of Competitiveness in Competitive Pricing,"working paper subsequently published 1997, Journal of the Academy of Marketing Science, 25 (2), 109-116.

Hendon, Donald W. (1986), Battling for Profits: How to Win Big on the Marketing Battlefield. Jonesboro, AR: Business Consultants International.

Jacobson, Robert and D. A. Aaker (1985), "Is Market Share All That It's Cracked Up to Be?" Journal of Marketing, 49 (Fall), 11- 21.

Kaplan, A. D. H., J. B. Dirlam, and R. F. Lanzillotti (1958), Pricing in Big Business. Washington, DC: The Brookings Institution.

Kiechel, Walter (1981), "The Decline of the Experience Curve," Fortune, (October 5), 139-46. Kohn, Alfie (1986), No Contest: The Case Against Competition. Boston: Houghton Mifflin.

Kotler, Philip (1988), Marketing Management: Analysis, Planning, Implementation and Control,6th ed. Englewood Cliffs, NJ: Prentice-Hall.

Kuhlman, D. Michael and A. F. J. Marshello (1975), "Individual Differences in Game Motivationas Moderators of Preprogrammed Strategy Effects in Prisoner's Dilemma," Journal of Personality and Social Psychology, 32 (5), 922-31.

Lanzillotti, Robert F. (1958), "Pricing Objectives in Large Companies," American Economic Review, 48 (5), 921-40.

Leeflang, Peter S. H. and D. R. Wittink (1996), "Competitive Reaction Versus CompetitiveResponse: Do Managers Overreact?" International Journal of Research in Marketing” (forthcoming).

Lieberman, Marvin B. (1987), "The Learning Curve, Diffusion, and Competitive Strategy," Strategic Management Journal, 8, 441-52.

Liebrand, W. B. G. and G. J. van Run (1985), "The Effects of Social Motives on Behavior in Social Dilemmas in Two Cultures," Journal of Experimental Social Psychology, 21 (1), 86-102.

Locke, Edwin A. (1986), Generalizing from Laboratory to Field Settings. Lexington, MA: Lexington Books.

-and G. P. Latham (1990), A Theory of Goal Setting and Task Performance. Englewood Cliffs, NJ: Prentice-Hall.

Messick, David M. and C. G. McClintock (1968), "Motivational Bases of Choice in Experimental Games," Journal of Experimental Social Psychology, 4 (1), 1-25.

-and W. B. Thorngate (1967), "Relative Gain Maximization in Experimental Games," Journal of Experimental Social Psychology, 3 (1), 85-105.

Montgomery, Cynthia A. and B. Wernerfelt (1991), "Sources of Superior Performance: Market Share Versus Industry Effects in the U.S. Brewing Industry," Management Science, 37 (8), 954-59.

Mueller, Dennis C. (1992), "The Corporation and the Economist," International Journal of Industrial Organization, 10 (1), 147-69.

O'Leary-Kelly, Anne M., J. J. Martocchio, and D. W. Frink ( 1994), “A Review of the Influence of Group Goals on Group Performance,” Academy of Management Journal, 37 (5), 1285-301.

Parks, Bill, S. W. Pharr, and B. D. Lockeman (1994), “A Marketer's Guide to Clausewitz: Lessons for Winning Market Share,” Business Horizons, 37 (July-August), 68-73. 
Porter, Michael E. (1980), Competitive Strategy: Techniques for Analyzing Industries and Competitors. New York: The Free Press.

Prescott, John E., A. K. Kohli, and N. Venkatraman (1986), “The Market Share-Profitability Relationship: An Empirical Assessment of Major Assertions and Contradictions," Strategic Management Journal, 7 (4), 377-94.

Scodel, Aivin, J. S. Minas, P. Ratoosh, and M. Lipetz (1959), "Some Descriptive Aspects of Two-Person Non-Zero-Sum Games,” Journal of Conflict Resolution, 3 (2), 114-19.

Shimp, Terence A., E. M. Hyatt, and D. J. Snyder (1991), "A Critical Appraisal of Demand Artifacts in Consumer Research," Journal of Consumer Research, 18 (3), 273-83.

Siegel, Sidney and N. J. Castellan, Jr. (1988), Nonparametric Statistics for the Behavioral Sciences. New York: McGraw Hill.

Sigall, H., E. Aronson, and T. van House (1970), "The Cooperative Subject: Myth or Reality?"Journal of Experimental Social Psychology, 6 (1), 1-10.

Slater, Robert (1993), The New GE: How Jack Welch Revived an American Institution. Homewood, IL: Business One Irwin.

Slater, Stanley F. and J. C. Narver (1994), "Does Competitive Environment Moderate the Market Orientation-Performance Relationship?” Journal of Marketing, 58 (January), 46-55.

- and T. J. Zwirlein (1992), "Shareholder Value and Investment Strategy Using the General Portfolio Model," Journal of Management, 18 (4), 717-32.

Suls, Jerry M. (1977), "Social Comparison Theory and Research: An Overview from 1954," in Social Comparison Processes, Jerry M. Suls and R. L. Miller, eds. New York: John Wiley \& Sons.

Szymanski, David M., S. G. Bharadwaj, and P. R. Varadarajan (1993), "An Analysis of the Market Share-Profitability Relationship," Journal of Marketing, 57 (July), I-18.

Teger, Allan I. (1980), Too Much Invested to Quit. New York: Pergamon.

Tschoegl, Adrian E. and C. J. Yu (1990), "Gibrat's Law in Marketing: The Case of Liquor BrandSales," International Journal of Research in Marketing, 7 (4), 249-62. 